problems) and stigma. For example, some cultures with strong family bonds can perceive mental disorders as something that would expose the family and affect its reputation. Structural-contextual barriers in Brazil include the lack of access to appropriate and culturally sensitive mental health services, due to the lack of staff members who understand and speak languages other than Portuguese, and the very small number of workers from minority groups or trained to work with people from different ethnic and cultural backgrounds. Brazil's political and racial context could also affect the capacity of adults and children to trust the mental health system to help them, especially among undocumented immigrants. These barriers are even more complex in small municipalities and far from major centers.

Reducing barriers to care and providing culturally appropriate mental health services is a significant challenge for professionals, policy makers, and migrant and refugee advocacy organizations. To cultivate best practices in assessment and diagnosis, clinicians could take various steps to examine consciously and take into consideration the extension of cultural and linguistic differences between patients and the predominant culture of Brazil. One way to do this is to recognize the dynamic nature of culture and incorporate cultural variables at all stages of the assessment process, e.g., by using culturally sensitive interviews or collecting data on acculturation, religious practices, racism/discrimination, and cultural values. The use of a contextual approach that takes the explanatory models of patients into account, and whereby patients could understand the medical hypothesis easily, would also be useful, as would assessment of the possibility of culture-related syndromes. Finally, for mental health professionals to have access to translators and work in partnership with the different cultural communities would greatly benefit the health services and help meet the needs of the growing number of immigrants and refugees in Brazil.

Lineth Hiordana Ugarte Bustamante, ${ }^{1,2}$ Emilie Leclerc, ${ }^{1,2}$ Jair de Jesus Mari, ${ }^{1,2}$ Elisa Brietzke ${ }^{1,2}$ ${ }^{1}$ Departamento de Psiquiatria, Universidade Federal de São Paulo (UNIFESP), São Paulo, SP, Brazil. ${ }^{2}$ Programa de Pós-Graduação em Psiquiatria e Psicologia Médica, UNIFESP, São Paulo, SP,

Brazil

Submitted Dec 07 2015, accepted Dec 182015.

\section{Disclosure}

The authors report no conflicts of interest.

\section{References}

1 Instituto Brasileiro de Geografia e Estatística (IBGE). Vamos conhecer o Brasil / nosso povo / migração e deslocamento [Internet]. [cited 2016 Jan 29]. 7a12.ibge.gov.br/vamos-conhecer-o-brasil/nosso-povo/migracaoe-deslocamento.

2 Arantes JT. O panorama da imigração no Brasil [Internet]. 2015 Jul 07 [cited 2015 Sep 23]. exame.abril.com.br/brasil/noticias/o-panorama-daimigracao-no-brasil.

3 Coutinho MPL, Rodrigues IF, Ramos N. Transtornos mentais comuns no contexto migratório internacional. Psico. 2012;43:400-7.
4 Lechner E. Imigração e saúde mental. Migracoes [Internet]. 2007 [cited 2016 Jan 29]. http://www.ceg.ul.pt/migrare/publ/migracoes1_ completo.pdf.

5 Waldman TC. Movimentos migratórios sob a perspectiva do direito à saúde: imigrantes bolivianas em São Paulo. Rev Dir Sanit. 2011;12:90-114.

6 Straiton M, Reneflot A, Diaz E. Immigrants' use of primary health care services for mental health problems. BMC Health Serv Res. 2014;14:341.

\title{
A neurofeedback protocol to improve mild anxiety and sleep quality
}

Rev. Bras. Psiquiatr. 2016;38:264-265

doi:10.1590/1516-4446-2015-1811

As most psychiatric disorders, anxiety and depression are conditions whose severity can be represented over continuums that range from subclinical manifestations (expectancy/fear without proper justification and low mood, respectively) to full-blown biosocial disabilities. From an endophenotypic perspective, alpha band $(8-12 \mathrm{~Hz})$ asymmetry in the left frontal cortex has emerged as the most prominent electroencephalographic (EEG) correlate of both anxiety and depression in right-handed people, followed by excessive band power in beta $1(12-20 \mathrm{~Hz})$ and beta 2 waves $(20-30 \mathrm{~Hz})$ in the right parietal lobe. ${ }^{1}$ Shared features also extend to the genetic level, where the presence of copies of the short variation of the 5-HTTLPR polymorphism increases the risk of both anxiety and depression.

EEG neurofeedback is an operant conditioning technique in which subjects learn to self-regulate and modify their brain activity through a feedback loop. In the recent past, induction of healthy alpha asymmetry ${ }^{2,3}$ and regulation of alpha power bands ${ }^{4}$ have been successfully used to treat anxiety and depression, whereas increasing the power of sensorimotor rhythm (SMR) bands - a sort of EEG activity ranging from 12-15 Hz over the sensorimotor cortex - has been used successfully to improve memory and sleep quality. ${ }^{5}$

We report the case of a 29-year-old woman, with no previous psychiatric history, who presented with anxiety symptoms, sleep problems, and mild cognitive impairments which she associated to a contingent situation she was facing. We assessed pre- and post-EEG data using a protocol reported elsewhere. ${ }^{3}$ Anxiety and depression symptoms were assessed using Beck scales (Beck Anxiety Inventory [BAI] and Beck Depression Inventory $[B D I])$, and sleep quality, with the Pittsburgh Sleep Quality Index (PSQI). Cognitive measures were also administered. A summary of results is presented in Table 1.

The training protocol lasted 20 sessions, during which the subject was trained to increase beta $1(12-15 \mathrm{~Hz})$ at $\mathrm{C} 4$ with eyes open, followed by closed-eyes training designed to increase the alpha/beta 3 ratio $(9.5-12 \mathrm{~Hz} / 23-38 \mathrm{~Hz})$ at $\mathrm{P} 4$. There was marked improvement of anxiety, depression, and sleep quality, as well as some improvement in executive functions (Table 1). From an endophenotypic viewpoint, there was an overall increase in beta 1, low alpha $(8-10 \mathrm{~Hz})$, and high alpha $(10-12 \mathrm{~Hz})$ powers and a decrease in beta 2 
Table 1 Pre- and post-treatment evaluations

\begin{tabular}{|c|c|c|c|}
\hline \multirow[b]{2}{*}{ Construct or domain } & \multirow[b]{2}{*}{ Task or inventory } & \multicolumn{2}{|c|}{ Score or time } \\
\hline & & Pre & Post \\
\hline Anxiety & Beck Anxiety Inventory* & 14 (mild) & 5 (minimum) \\
\hline Depression & Beck Depression Inventory* & 11 (minimum) & 3 (minimum) \\
\hline Sleep quality & Pittsburgh Sleep Quality Index & 9 (poor) & 4 (good) \\
\hline \multirow[t]{2}{*}{ Cognitive flexibility } & Trail Making B & $65 \mathrm{~s}$ & $43 \mathrm{~s}$ \\
\hline & Stroop (task switching) & $53 \mathrm{~s}$ & $43 \mathrm{~s}$ \\
\hline Selective attention & Stroop (response inhibition) & $48 \mathrm{~s}$ & $46 \mathrm{~s}$ \\
\hline Attention & CPT total score & 2.0890 & 2.4812 \\
\hline Planning & Tower of Hanoi (accuracy ratio) & 1.78 & 1.27 \\
\hline
\end{tabular}

CPT = Continuous Performance Test.

* Classification cutoffs based on the validated Brazilian version of the instrument.

Detailed results are available at: https://drive.google.com/file/d/0ByRmzoh7IRqBUENzWUY1YIpGaW8/view? usp=sharing

(a stress biomarker). Low and high alpha changes from the pre-treatment baseline were particularly prominent at $\mathrm{P} 4$, increasing from 8.9 to $14 \%$ and from 12.2 to $26.2 \%$ respectively. These results are encouraging and suggest that neurofeedback can be used as an adjunct in the treatment of subclinical anxiety and, perhaps, other psychiatric conditions, with minimal risk and low technology costs.

The use of an alpha/beta 3 ratio neurofeedback protocol is not well documented in the literature, and seems to have potential efficacy for reducing anxiety and associated symptoms. In this case, the combination of two protocols - SMR followed by alpha/beta 3 ratio - led to an overall improvement in the symptoms reported by the patient. To the best of our knowledge, this is the first time such a combination has been used. Although our initial findings are promising, caution is needed in their interpretation, and these results should be replicated in larger, controlled clinical trial settings. Moreover, the specific effects of SMR and of alpha/beta 3 training for anxiety should be investigated separately.

July S. Gomes, Daniella V. Ducos, Henrique Akiba, Álvaro M. Dias

Departamento de Psiquiatria, Universidade Federal de São Paulo (UNIFESP), São Paulo, SP, Brazil

Submitted Sep 09 2015, accepted Jan 112016.

\section{Acknowledgements}

JSG receives a scholarship from Coordenação de Aperfeiçoamento de Pessoal de Nível Superior (CAPES). AMD has received a grant from Fundação de Amparo à Pesquisa do Estado de São Paulo (FAPESP; protocol no. 2015/3931-0).

\section{Disclosure}

The authors report no conflicts of interest.

\section{References}

1 Pavlenko VB, Chernyi SV, Goubkina DG. EEG correlates of anxiety and emotional stability in adult healthy subjects. Neurophysiol. 2009;41:337-45.

2 Kerson C, Sherman RA, Kozlowski GP. Alpha suppression and symmetry training for generalized anxiety symptoms. J Neurother. 2009; 13:146-55.

3 Dias AM, van Deusen A. A new neurofeedback protocol for depression. Span J Psychol. 2011;14:374-84.

4 Wang S, Zhao Y, Chen S, Lin G, Sun P, Wang T. EEG biofeedback improves attentional bias in high trait anxiety individuals. BMC Neurosci. 2013;14:115.

5 Schabus M, Heib DP, Lechinger J, Griessenberger H, Klimesch W, Pawlizki $A$, et al. Enhancing sleep quality and memory in insomnia using instrumental sensorimotor rhythm conditioning. Biol Psychol. 2014;95:126-34. 